\title{
MEETINGS OF SOCLETIES.
}

\section{THE ROYAL MEDICO-CHIRURGICAL SOCIETY OF GLASGOW.}

SESSION 1928-1929.

Meeting XI.—5тth ApriL, 1929.

The President, Dr. Joshua Ferguson, in the Chair.

\section{DISCUSSION ON THE ESTIMATION OF OPERATION RISK.}

The discussion was opened by Mr. Matthew White and Dr. A. K. Glen, the following joint communication being read by the former :-

The risks incurred by a patient in undergoing an operation under general anæsthesia have always been recognized, and their recognition is evident in the teaching of the standard surgical text-books regarding the routine procedures to be adopted in the examination of a patient before operation. These procedures include as essential a thorough examination of (1) the heart, (2) the lungs, and (3) the urine. In addition, certain types of case require further investigation, e.g., urinary cases in which tests are carried out to ascertain the efficiency of the kidneys, or goitre cases in which the basal metabolism is investigated. With the aid of such tests many conditions may be recognized which, by their presence, materially increase the risks incurred by a patient in undergoing operation, e.g., myocardial disease, chronic bronchitis, nephritis, diabetes, \&c. Again, there are well recognized risks associated with emergency operations by reason of the condition of the patient, e.g., shock, sepsis, or toxæmia. Lastly, certain operative procedures involve special risks on account of technical difficulties or long duration. 
The object of this paper, however, is to draw attention to another aspect of operation risk which may best be illustrated by a brief description of two cases.

1. Mrs. H., aged 42 years, was admitted to hospital complaining of typical attacks of gall-stone colic extending over a period of three years; the last attack being followed by well-marked and persistent jaundice. At operation a large gall-stone was found impacted in the common duct, and several smaller stones were also present in the gall-bladder. The large stone was removed from the common duct and a considerable quantity of " white bile " drained away. The gall-bladder and duct were drained after removal of the stones, and, in addition, a small cigarette drain was led down to the common duct. Both tubes and drain were brought out through a separate stab wound laterally. It is the subsequent history of the case to which we wish especially to draw your attention. The jaundice was distinctly less after twenty-four hours, but thereafter increased a little but was of somewhat different type, being rather pale yellow and reminding one of a pernicious anæmia. The patient recovered from the initial shock but remained rather weak and listless with no inclination for nourishment. The tongue was moist and there was no complaint of thirst. The pulse was fairly good though rather soft at times. There was practically no vomiting save an occasional mouthful after a drink. There was no distension of the bowel till the fifth day, when a slight degree of fulness of the abdomen was noted. The bowels moved twice without aperients during this time, and the second motion was well coloured. She had been having glucose per rectum as a routine, and on one occasion an intracellular saline was administered.

On the fourth day an intravenous injection of $15 \mathrm{oz}$. of 5 per cent glucose was given with in addition 10 units of insulin. A marked improvement followed this injection-the patient felt better and looked better and took nourishment well. Then she became dull and listless again with no desire for fluids. There was no complaint of thirst or pain or any discomfort. Temperature was normal and remained normal throughout. On the fifth day another intravenous injection of glucose, $16 \mathrm{oz}$., with 10 units of insulin was given, and this was again followed by temporary improvement, lasting for twelve hours. The drainage of bile, which had been averaging 3 to $4 \mathrm{oz}$., then lessened and finally ceased. Further intravenous injections were followed by improvement lasting only a few hours, and she finally died on the seventh day. The output of urine had been fair until the sixth day, and then suddenly dropped to a few ounces, which seemed mostly blood. The wound had been dressed twice during this time, and showed nothing abnormal.

The second case was that of a young girl, aged 24 years, who had a fissurein-ano. Her general condition seemed excellent: heart, lungs, and urine normal. She had had her appendix removed eighteen months previously, and at that time was very sick for three days after operation. The fissure was excised under general anæesthesia-mostly chloroform-and the patient was under the anæsthetic altogether about fifteen minutes. She started to vomit half an hour after the operation, and continued to do so intermittently for six days. By that time, in spite of a fair intake of fluids, she was becoming dehydrated, but, fortunately, the sickness then ceased and she made a good recovery.

These two cases represent somewhat extreme forms of postoperative disturbance, but every surgeon must be familiar with the type of case which fails to display the normal peaceful convalescence expected. After a simple operation such as herniotomy or appendicectomy, the patient has persistent sickness with nausea-poor output of urine, "toxic " appear- 
ance verging upon actual jaundice-even at times suggesting a condition of delayed chloroform poisoning. The occasional occurrence of such cases led Dr. Glen and myself to consider very carefully if there were not at our disposal some means of ascertaining the type of case likely to show such stormy convalescence and, if possible, of preventing its development. The cases at the Elder Hospital are all recommended cases; no emergency or accident cases being admitted. The patients are in general in good health apart from the actual condition for which they seek relief. In such circumstances there should be no excuse for any anxiety other than that associated with the particular operative procedure.

In considering the possibilities it seemed to us that the external factors of diet, pre-operative treatment, anæsthesia, $\& c$. , were sufficiently uniform and standardized in the hospital to enable us to eliminate them as causal factors. We were thus inclined to look in the direction of the patient for an explanation of their reaction to operation. It seemed possible that a large proportion of these unexpected complications were due to some latent maladjustment of metabolism not capable of detection by the routine methods of examination. The effect of pre-operative treatment, the shock of operation, and the anesthetic was to exaggerate this pre-existing instability to the extent of producing clinical signs and symptoms.

Our attention was thus directed towards obtaining some method of examination, clinical or laboratory, which would enable us to detect beforehand those patients whose metabolism was unstable and who were likely to react severely to operative procedures. We were particularly anxious to avoid any elaborate biochemical tests for which we had neither the time, training, nor facilities. In clinical work any biochemical test, to be of practical value, must be simple and capable of application as a routine method. Any attempt by the clinician to undertake elaborate biochemical tests lays him open to the criticism of the physiologist or biochemist, who will point out the many sources of error and fallacies that render the test inaccurate and therefore useless. To employ simple tests and to correlate them with the results of clinical examination was our aim. We therefore directed our attention to the urine in the hope that a more careful and detailed 
examination thereof might afford some indication of a disturbance of metabolism such as would account for the onset of untoward post-operative symptoms. The method of examination adopted was as follows:-The total urine passed during the twenty-four hours immediately preceding operation was collected in a Winchester to which a few drops of chloroform had been added as a preservative. Similarly the urine passed during the twenty-four hours after operation was collected. The usual routine tests were carried out, viz., reaction, specific gravity, albumen, sugar, and acetone. In addition, the following examinations were made:-(1) Estimation of urea by the usual sodium hypobromite method; (2) estimation of the total free acids present by titration with deci-normal caustic soda, using phenolphthalein as an indicator; (3) estimation of the amount of acid in combination with ammonia by the method of Sørensen; (4) estimation of the hydrogen ion concentration by means of indicators, the apparatus used being the "capillator" set provided by Messrs. British Drug Houses Limited. This capillary method is quick, convenient, and simple in use and gives results sufficiently accurate for practical purposes. We are well aware, of course, of the number of variable and unknown factors which enter into such a method of investigation, and in the interpretation of results in any individual case the margin of error is considerable. Nevertheless, the results of some 200 investigations have been suggestive in a number of ways. For control purposes two other tests were employed in a certain number of cases, viz., (1) the carbon dioxide combining power of the blood was estimated by Van Slyke's apparatus, and (2) the estimation of the blood urea by the urease method. These two tests are, of course, more elaborate and difficult to carry out and cannot fairly be described as side-room tests, but the other four referred to are simple in use and occupy only a few minutes, and it is to them that we wish to direct your attention.

1. The volume and specific gravity of the urine.-So many factors influence the output of urine that little importance can be attached to this. In addition, the difficulty of obtaining an accurate measurement in women makes the figures unreliable. Several interesting results emerged, however. The 
Table I. - Twexty-four Hours before Operation.

\begin{tabular}{|c|c|c|c|c|c|c|c|c|c|c|c|c|c|c|c|}
\hline $\begin{array}{l}\dot{0} \\
\text { జँ } \\
0 \\
\ddot{0} \\
\dot{0} \\
\dot{y}\end{array}$ & Diagnosis. & Sex. & Age. & $\frac{\stackrel{\dot{\Xi}}{\Xi}}{\grave{\Xi}}$ & Sp. Gr. & $\mathrm{pH}$. & Alb. & Sugar. & 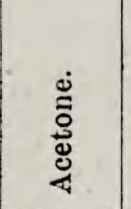 & 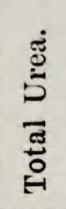 & $\begin{array}{l}\text { Total } \\
\text { Free } \\
\text { Acid. }\end{array}$ & 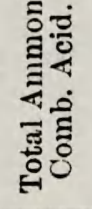 & 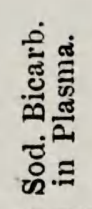 & 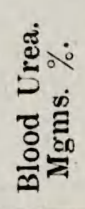 & Condition after Operation. \\
\hline 116 & Appendix. & M. & 19 & 1280 & 1014 & $9 \cdot 2$ & $\ldots$ & $\ldots$ & $\ldots$ & 13 & 0 & 727 & $62 \%$ & Ne. & $\ldots$ \\
\hline 118 & Appendix. & F. & 30 & 740 & 1020 & $5 \cdot 8$ & $\ldots$ & $\ldots$ & Trace. & 10 & $18 \cdot 8$ & 30 & $62 \%$ & 21 & $\ldots$ \\
\hline 117 & L.I. hernia. & M. & 55 & 1000 & 1012 & $8 \cdot 6$ & $\ldots$ & $\cdots$ & $\cdots$ & 11 & 0 & 220 & $45 \%$ & 24 & $\cdots$ \\
\hline 119 & Hallux valgus. & F. & 25 & 640 & 1026 & $5 \cdot 0$ & $\ldots$ & $\ldots$ & $\ldots$ & 17 & 97 & 120 & $48 \%$ & 29 & $\ldots$ \\
\hline
\end{tabular}

Twenty-four Hodrs after Operation.

\begin{tabular}{|c|c|c|c|c|c|c|c|c|c|c|c|c|c|c|c|}
\hline 116 & Appendix. & M. & 19 & 1120 & 1036 & $6 \cdot 8$ & $\ldots$ & $\ldots$ & + & 44 & 340 & 1120 & $\ldots$ & $\ldots$ & 1 day's vomiting; slight. \\
117 & L. I. hernia. & M. & 55 & 570 & 1026 & $5 \cdot 6$ & Trace. & $\ldots$ & Trace. & 18 & $95 \cdot 7$ & 137 & $\ldots$ & $\ldots$ & 1 day's vomiting; slight. \\
118 & Appendix. & F. & 30 & 510 & 1034 & $5 \cdot 4$ & $\ldots$ & $\ldots$ & Trace. & 22 & $93 \cdot 8$ & $53 \cdot 4$ & $\ldots$ & $\ldots$ & 3 days' vomiting; severe. \\
119 & Hallux valgus. & F. & 25 & 540 & 1032 & $5 \cdot 2$ & $\ldots$ & $\ldots$ & ++ & 25 & 128 & 162 & $\ldots$ & $\ldots$ & 2 days' vomiting; slight. \\
\hline
\end{tabular}


Table II.-Twenty-Four Hours before Operation.

\begin{tabular}{|c|c|c|c|c|c|c|c|c|c|c|c|c|c|c|c|}
\hline 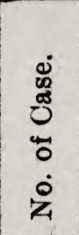 & Diagnosis. & Sex. & Age. & $\stackrel{\stackrel{0}{\Xi}}{\vdots}$ & Sp. Gr. & $\mathrm{pH}$. & Alb. & Sugar. & 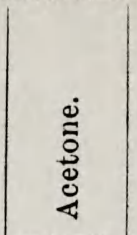 & 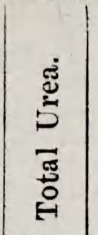 & $\begin{array}{l}\text { Total } \\
\text { Free } \\
\text { Acid. }\end{array}$ & 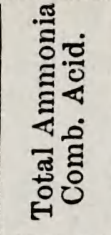 & 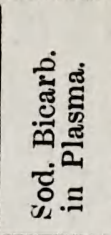 & 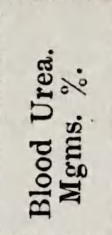 & Condition after Operation. \\
\hline 55 & $\begin{array}{c}\text { Duodenal ulcer } \\
\text { Gastro- } \\
\text { enterostomy. } \\
\text { Do. }\end{array}$ & $\begin{array}{l}\text { M. } \\
\text { M. }\end{array}$ & 47 & 2000 & 1012 & $9 \cdot 0$ & $\cdots$ & $\cdots$ & $\cdots$ & $12 \cdot 5$ & 0 & 2480 & $\begin{array}{l}58 \% \\
50 \%\end{array}$ & 54 & $\begin{array}{l}\mathrm{HCl}=\cdot 28 \% \\
\mathrm{HCl}=\cdot 3 \%\end{array}$ \\
\hline 240 & $\begin{array}{l}\text { Gastric ulcer. } \\
\text { Gastrectomy. }\end{array}$ & F. & 35 & 700 & 1020 & $7 \cdot 1$ & $\cdots$ & ... & + & 15 & 56 & 112 & $58 \%$ & 20 & $\mathrm{HCl}=\cdot 14 \%$ \\
\hline 74 & Gall-stone. & F. & 49 & 300 & 1014 & $5 \cdot 4$ & $\ldots$ & ... & Trace. & 10 & $26 \cdot 4$ & $13 \cdot 2$ & $42 \%$ & Ne. & $\ldots$ \\
\hline 77 & Do. & F. & 42 & 400 & 1015 & $5 \cdot 0$ & $\cdots$ & $\cdots$ & $\cdots$ & $7 \cdot 5$ & $30 \cdot 6$ & $39 \cdot 6$ & $44 \%$ & 50 & ... \\
\hline 157 & Do. & F. & 34 & 110 & 1026 & $6 \cdot 2$ & ... & $\cdots$ & Trac. & $5 \cdot 9$ & $3 \cdot 5$ & $2 \cdot 97$ & $68 \%$ & 46 & $\cdots$ \\
\hline \multicolumn{16}{|c|}{ Twenty-Four Hours after Operation. } \\
\hline 51 & Duodenal ulcer & M. & 47 & 870 & 1026 & $8 \cdot 0$ & $\cdots$ & $\cdots$ & $\ldots$ & 22 & 0 & 874 & $\mathrm{Ne}$. & $\mathrm{Ne}$. & $\begin{array}{l}\text { No romiting; good con- } \\
\text { valescence. }\end{array}$ \\
\hline 55 & Do. & M. & 55 & 1110 & 1020 & $7 \cdot 0$ & $\cdots$ & $\begin{array}{c}\text { Green. } \\
\text { Red. }\end{array}$ & $\ldots$ & 24 & 198 & 837 & Ne. & Ne. & 4 days' vomiting; severe. \\
\hline 240 & Gastric ulcer. & F. & 35 & 750 & 1024 & $5 \cdot 0$ & $\ldots$ & $\cdots$ & ++ & 22 & $2 \% 0$ & 936 & $\mathrm{Ne}$. & Ne. & None; good convalescence. \\
\hline 74 & Gall-stones. & F. & 49 & 250 & 1028 & $5 \cdot 0$ & $\cdots$ & $\begin{array}{c}\text { Green. } \\
\text { Red. }\end{array}$ & ++ & 6 & 26 & 25 & Ne. & $\mathrm{Ne}$ & 5 days : severe. \\
\hline 77 & Do. & F. & 42 & 230 & 1026 & $4 \cdot 6$ & $\ldots$ & $\begin{array}{c}\text { Green. } \\
\text { Red. }\end{array}$ & $\ldots$ & $7 \cdot 5$ & 29 & 19 & $\mathrm{Ne}$. & Ne. & 6 days; died. \\
\hline 157 & Do. & F. & 34 & 500 & 1036 & $5 \cdot 2$ & Trace. & $\left|\begin{array}{c}\text { Green. } \\
\text { Red. }\end{array}\right|$ & Trace. & 18 & 135 & 160 & Ne. & $\mathrm{Ne}$. & 2 days; slight discomfort. \\
\hline
\end{tabular}


output of urine in many patients remained remarkably constant in spite of variation in the intake of fluids. Or rather, to put it more accurately, the output of solids as measured by the volume of urine and the specific gravity remained very constant for any individual patient. An increase in fluid intake was usually followed by increased urine output, but such urine usually showed a low specific gravity. It is easy to increase the output of fluid, but we found it very difficult to produce any increase in the output of urine of a similar specific gravity. Nearly all the gall-stone cases had a persistently low urine output, and we were struck by the disinclination of such patients to drink fluid. It was with difficulty that they could be persuaded to increase their fluid intake. In Table II the figures for three gall-stone cases show the low output which was characteristic. In general we noted that cases which had a persistently low urine output tended to have more postoperative sickness than those whose output was normal. Thus, in Table I cases 118 and 119 had more sickness than 116 and 117. Of 54 cases which had an output of less than 500 c.c., 40 per cent had post-operative vomiting of more than two days. Of 60 cases with an output of over 1,000 c.c., only 16 per cent had two days' sickness. A low output was nearly always associated with a very acid urine, i.e., a urine with a high hydrogen ion concentration. This finding agrees with the statement made in some text-books of physiology to the effect that cases of acidosis, whether compensated or not, tend to retain fluid in an attempt to dilute the acids.

2. The hydrogen ion concentration of the urine.-The figures representing the hydrogen ion concentration are recorded in the tables according to the logarithmic method of Sørensen. Thus, a $\mathrm{pH}$ of $7 \cdot 2$ represents neutrality. The more acid the urine contains the lower the $\mathrm{pH}$ figure and vice versa. It must be remembered, however, that this figure does not correspond with the titratable acidity. For example, tenth normal hydrochloric acid with a $\mathrm{pH}$ of 1.04 is neutralized by the same amount of tenth normal sodium hydroxide as tenth normal acetic acid, of which the $\mathrm{pH}$ is 2.88 . Moreover, a salt of a strong base and a weak acid, although neutral to titration, may show a high $\mathrm{pH}$ figure, i.e., on the alkaline side. The capillary method, though simple and convenient, has one disadvantage. When used for 
testing dilute urines of low specific gravity there may be so few " buffer" salts present that the relatively large quantity of the indicator used may affect the result appreciably. It is also very important to ensure that the urine is not left exposed to the air for even a short time, as the $\mathrm{pH}$ figure may alter considerably in such circumstances. Even allowing for such discrepancies, however, the $\mathrm{pH}$ figures showed some interesting results. In every case without exception there was a fall in the $\mathrm{pH}$ after operation, i.e., the urine became more acid. Taking post-operative sickness as an indication of the patients' condition, it was noted that of 27 cases whose urine gave a $\mathrm{pH}$ of less than 6 the average duration of sickness was 1.9 days, while of 34 cases with a $\mathrm{pH}$ of over 8 the average duration of sickness was 0.67 days. Gall-stone cases always have a very low $\mathrm{pH}$ figure after operation, e.g., 46, and as a rule they have more sickness than the average case.

3. Acetonuria.-Of some 300 cases admitted to the Elder Hospital with a view to operation, 7 per cent gave a positive result when tested for the presence of acetone in the urine. Sometimes the acetone disappeared before operation, while some cases which gave a negative result on admission became positive before operation. The appearance of acetone in the urine as a result of starvation or drastic purgation is well known; but in the preparation of the patients at the Elder Hospital as elsewhere such methods are no longer employed. In spite of the avoidance of such pre-operative treatment, it was not uncommon to find acetone in the urine. In common with other observers we noted that acetonuria was commonly present in nervous or apprehensive patients.

The appearance of acetone in the urine after operation was, of course, frequent, but we could find no relationship between the post-operative condition and the presence of acetone. On the whole, those who vomited after operation more than usual showed acetone more frequently than the others, but the acetone was probably the result of the vomiting. While the presence of acetone and diacetic acid in the urine may be associated with a true acidosis, it must be remembered that they may be present even if the acidosis is compensated and there is no diminution in the alkali reserve. Indeed, they may be present in a condition of alkalosis. We have found it

No. 6.

Vol. CXI. 
comparatively easy to cause the disappearance of acetone from the urine by the administration of glucose, or by suitable diet. - 4. The free and ammonia-combined acids.-The total free acid was estimated by direct titration with tenth normal sodium hydroxide, using phenolphthalein as an indicator. The figures on the charts represent the number of cubic centimetres of tenth normal sodium hydroxide required to neutralize the total free acid excreted in twenty-four hours. By the addition of formalin to the neutral solution remaining after this titration, the acids present in combination with ammonia are liberated, and were then titrated against tenth normal sodium hydroxide as before. This second titration covers the aminoacids as well as the ammonia-combined acids, but for practical purposes the figures may be taken to represent the ammonia content of the urine.

In estimating the total acid output in the urine these two forms of acid, free and combined, must be estimated separately.

This method of investigation proved of considerable interest, and there are several points which merit brief comment.

In the ordinary processes of metabolism there is a constant production of acids which the body requires to get rid of. Apart from direct excretion of $\mathrm{CO}_{2}$ by the lungs the usual method of excretion is by means of neutralization of the acids by means of an alkali and excretion of the salts so produced by way of the urine. The free acid salts in the urine may thus be taken to represent the results of neutralization by means of the fixed bases, e.g., the alkaline sodium phosphate loses some of its base and is excreted as the acid sodium phosphate. Again ammonia is largely employed to neutralize acids and appears in the urine in the form of the neutral ammonium salts already referred to. In this connexion it must be remembered that the kidney plays an important part in the production of ammonia, and if that organ is diseased there may be little or no appearance of ammonium salts in the urine even in well-developed acidosis. For this reason we have not included in our series any case in which there was a definite degree of nephritis.

Further, if the liver function be impaired the metabolism of proteins may be interfered with and the normal production of urea and subsequently ammonia may fail. In such cases one would expect a poor output of the ammonia combined acids. Table II shows this very clearly in the figures taken from three gall-stone cases where one would expect some impairment of liver function. In parenthesis, it should be noted that in most physiology textbooks the statement is made that in cases of liver failure there is a large excretion of ammonia in the urine-the reverse of what we found in the gall-stone cases.

Another interesting point is shown in the same table-the contrast between the gastric or duodenal cases and the gall-stone cases. Almost always we found that cases of duodenal ulcer had a very low free acid output and a high ammonia combined acid output. A neutral or slightly alkaline urine was almost invariably found in such cases. There may be some association between loss of $\mathrm{HCl}$ in the gastric juice and the low acid output, e.g., Case 51 had 0.28 per cent of free $\mathrm{HCl}$ in the gastric analysis, while Case 105 had 0.3 per cent.

Some observers attach little importance to the actual output and lay stress 
upon the ratio of the free to the combined acid. Thus Ellis 1 states that the normal ratio is roughly $1-2$, and that an approach to a ratio of $1-1$ indicates a tendency towards an acid type of metabolism, while a ratio of 1.3 or more indicates an alkaline type. Davis and Rixon 2 give the normal range of ratio as 1-6 to 1-1.5. Barber and Oriel ${ }^{3}$ give the normal ratio as $1-1$, and state that rarely if ever does the ratio exceed this.

In our series the patients in whom the free-combined acid ratio exceeded unity invariably had a stormy convalescence; and if now we find a patient with a pre-operative ratio exceeding unity we prefer to defer operation and make some attempt to lower the ratio. A rapid rise in the combined acids after operation can be interpreted as a good sign. The lowest figure in our series was found in the gall-stone case which died.

It would appear that the two forms of acid excretion are not mutually compensatory. There may be no free acid present, in which case it is usual to find a good output of the combined acid, but a low combined acid output cannot be entirely compensated for by an increase in the free acid. We have never found any case with a complete absence of combined acid.

5. Total urea output of the urine.-The estimation of the urea in the urine is not regarded as of value, since it is affected by so many variable factors. Nevertheless, inasmuch as the liver is the organ responsible for the production of urea and we were inclined to believe that some disturbance of liver function was partly responsible for the post-operative difficulties, the estimation of the urea was included in the tests. It has usually been stated by the physiologists that the more ammonia employed in the neutralization of acids the less will be the urea excretion. Our results hardly seem to bear this out. For example, the cases which were very ill after operation often showed a low ammonia-acid output and at the same time a low urea output. On the other hand, many cases which did well showed a considerable increase in the urea output with at the same time a large ammonia-acid output. A good output of urea before operation was usually of good significance, in spite of the fact that it might be associated with a high blood urea.

6. The blood urea.-The blood urea was estimated by a urease method in 80 cases before operation. In certain cases of renal disease and in prostate cases the blood urea was, of 
course, high, but high figures were also obtained in a number of cases where we had no reason to expect them. Yet, in spite of a high blood urea, many such cases seemed to have a peaceful convalescence, while others were rather ill. Most of the gall-stone cases showed a high blood urea. Some apparently normal healthy individuals require a fairly high head of urea in the blood before the daily amount of urea can be got rid of.

7. The $\mathrm{CO}_{2}$ combining power of the blood was estimated by Van Slyke's apparatus in 42 cases before operation. Most of them seemed to be approximately normal. The two lowest figures were (1) 34 c.c. per cent in a young woman with a femoral hernia. She made a good recovery. (2) 35 c.c. per cent in a fat elderly woman with a large ventral hernia, who was rather ill after operation. These two tests last mentioned were outwith our original intention, which was to confine our investigations to such simple tests as could be carried out in a ward side-room by anyone not possessed of special training in biochemical methods.

The conclusions we have reached so far as a result of our investigations may be summarized briefly somewhat as follows:- In the first place, it is fair to assume that the average normal individual possesses a margin of reserve in his metabolism as in any other of his vital processes. There must, however, be a percentage of individuals whose margin of reserve is minimal: who are living, as it were, in a state of compensation. In such people the additional strain thrown on their metabolism by means of an operation performed under general anæsthesia is sufficient to use up their margin of reserve and break down their compensation. While a normal individual with sufficient reserve would show little or no clinical signs of the strain on his metabolism, the compensated individual fails under the strain and the clinical signs and symptoms of metabolic disturbance are manifest.

In the second place, the disturbance of metabolism may be regarded as manifesting itself in three types of patient. This classification is by no means well defined, but we found it useful in estimating the probable reaction of any individual patient. (1) The patient who shows evidence of a ketosis by the presence of acetone or diacetic acid in the urine. We 
need not concern ourselves with the actual cause of such ketosis whether associated with nervous disturbance, with impaired carbohydrate metabolism, with fasting, or with long-continued constipation. In most cases the condition is easily dealt with. In our series they were the least troublesome to deal with. The administration of glucose, or even a liberal diet, will usually suffice to cause the disappearance of acetone and diacetic acid from the urine. In the graver forms associated with diabetes the patient may be unable to utilize such extra supply of carbohydrate, and the administration of insulin in addition may be called for.

(2) The second class of case is that represented by the gallbladder cases, which have an inefficient liver. The organism is deprived of one method of acid neutralization and easily falls into a state of acid intoxication. If the liver of such a case is further damaged by the administration of an anæsthetic a grave risk is run if compensation fails.

(3) There is a third class of case in which an additional factor is introduced, viz., a defective kidney, i.e., defective in respect of ammonia excretion. This type of defect is naturally closely associated with the urea output, and the ultimate result in such cases seems to be a urcemic acidosis in which the ammonia excretion is low, contrary to the other forms of acidosis.

It may be of interest in this connection to quote from an address delivered by Lord Moynihan a few years ago :-

"Hepatic insufficiency and acidosis are difficult conditions to master. Of the former we now recognise two types. There is one in which the amount jaundice deepens ominously; the mind becomes obtuse; vomiting develops; the pulse becomes slower, the patient more and more enfeebled; drowsiness precedes coma, and the blood urea steadily increases; renal failure, consecutive to hepatic failure, is then the cause of death. And there is another in which, after a normal course of from three to eight days, the bile discharged becomes copious, thin, and pale; jaundice does not change perceptibly; restlessness, great prostration, profound muscular weakness, and a peevish irritability are noticed; vomiting is present but is not as a rule severe; blood urea remains low ; failure of the liver function is the cause of death."

In reviewing the results of our investigation in an endeavour to estimate the probable reaction of a patient to the strain of operation we arrived at the following tentative conclusion :1. If the urine examination showed-(a) a low output of urine of high specific gravity; (b) a low $\mathrm{pH}$ figure; (c) a high 
output of free acid; and $(d)$ a ratio of free to combined acid exceeding unity-then we regarded such a patient as having little or no reserve to stand the strain of operation.

2. We endeavoured to improve the reserve by various methods of treatment.

The line of treatment suggested was as follows:-

1. It seemed possible that, since a low output of urine was nearly always associated with a high specific gravity of urine, the body might be induced to excrete retained acids in greater quantity if sufficient volume of fluid were given to dilute the

Table IIi. - Showing effect of Pre-operative Treatment in Case of Gall-stones (Fenale, aged 42).

\begin{tabular}{|c|c|c|c|c|c|c|c|c|}
\hline Date. & Volume. & Sp. Gr. & $\mathrm{pH}$. & Alb. & Sugar. & Acetone. & $\begin{array}{l}\text { Total } \\
\text { Free } \\
\text { Acid. }\end{array}$ & $\begin{array}{c}\text { Total } \\
\text { Ammioni } \\
\text { Combi. } \\
\text { Acid. }\end{array}$ \\
\hline $26 / 10 / 28$ & 200 c.c. & 1030 & $5 \cdot 0$ & Trace. & $\ldots$ & $\ldots$ & 88 & 168 \\
\hline $5 / 11 / 28$ & 450, & 1030 & $5 \cdot 0$ & Trace. & $\ldots$ & $\ldots$ & 234 & 194 \\
\hline $12 / 11 / 28$ & 1350, & 1012 & $7 \cdot 7$ & Trace. & $\ldots$ & $\ldots$ & $64 \cdot 8$ & 54 \\
\hline $14 / 11 / 28$ & 1750 & 1018 & $7 \cdot 7$ & Trace. & $\ldots$ & $\ldots$ & 56 & 70 \\
\hline \multicolumn{9}{|c|}{ 20/11/28.,-OPERATION. } \\
\hline $21 / 11 / 28$ & 600 c.c. & 1026 & $5 \cdot 0$ & + & $\cdots$ & $\ldots$ & 528 & 396 \\
\hline $26 / 11 / 28$ & 1000 & 1012 & $6 \cdot 5$ & + & $\cdots$ & $\ldots$ & 80 & 340 \\
\hline $29 / 11 / 28$ & 1600, & 1018 & $6 \cdot 7$ & Trace. & $\ldots$ & $\ldots$ & 96 & 112 \\
\hline
\end{tabular}

salts. Abundant administration of fluid (water) was therefore tried. In some cases this resulted merely in a large output of urine of low specific gravity. Nevertheless in many cases there did appear to be a definite increase in the excretion of salts, as estimated by the total output of urine plus specific gravity.

2. In the cases associated with hepatic insufficiency-or shall we say with difficulty in utilizing their carbohydrate reserve? - the administration of glucose was tried. By mouth, by rectum, or intravenously. We do not propose to discuss at the moment the question of the absorption of glucose from 
the rectum. It was previously stated by some observers that there occurred a definite rise in the blood sugar after the administration of glucose per rectum, but recently others have shown that there is no such rise. There is at least general agreement that the intravenous route is undoubtedly the most effective and the quickest. Again, in some cases the difficulty apparently was that as in the diabetic, there was an inability to make use of the store of carbohydrate present, and the addition of insulin in such cases was essential.

3. In cases of acidosis where there was reason to believe that the supply of fixed bases was deficient the administration of alkali was tried. A mixture of sodium bicarbonate, sodium phosphate, and sodium sulphate equal parts was given. ziii t.i.d.

4. An attempt was made to stimulate the liver by the administration of calomel, salts, and in some cases of proprietary drugs such as "Felamine," which contain cholic acid and hexamine.

5 . The diet was modified by reducing the protein intake, by increasing the carbohydrates, by reducing the fats, and by giving abundance of green vegetables and fruit.

To illustrate the results of such pre-operative treatment we have drawn up Table III, which is a record of a woman aged 52 years suffering from gallstones. On admission the output of urine was only 200 c.c., the $\mathrm{pH} 5$, the free combined acid ratio 1-2 and a high ammonia acid output relatively to the total urine output. By the end of nearly three weeks the output had increased to 1,750 c.c., the $\mathrm{pH}$ had risen to 7.7 , the acid ratio was $1-1.2$ and the excretion of both forms of acid had reached a more normal figure. The immediate effect of operation was to reduce the output considerably, and to send up the acid excretion to enormous heights considering the output. There was also a swing of the ratio well above unity, and the $\mathrm{pH}$ dropped again to 5. The patient had slight sickness for twenty-four hours, and thereafter had an uneventful convalescence, and the urine tests showed a quick return to normal figures.

Summary and conclusions.-1. Attention is drawn to the occurrence in certain cases of more or less severe post-operative sickness and acid intoxication, and to the absence of any satisfactory method of recognizing before operation the patients who are likely to show such post-operative disturbance of metabolism.

2. The suggestion is made that a more exhaustive examination of the urine than the usual routine method might be found 
to give some indication of the type of metabolism likely to show gross post-operative disturbance.

3. Various simple tests are described such as can easily be carried out in a ward side-room without the necessity of elaborate equipment-(1) the estimation of the total output of urine in twenty-four hours, together with the specific gravity; (2) the estimation of the hydrogen ion concentration by the capillary method, using colour indicators; (3) the titration of the urine for the presence of free and ammoniacombined acids by the method of Sørensen, and the estimation of both the total quantities of each and of the ratio of free to combined acid.

4. The results are described of a series of such tests carried out in 200 cases before and after operation and compared with the clinical conditions.

5. Certain conclusions are reached as to the results which indicate the type of patient likely to react severely to the strain of operation under general anæsthesia, e.g., a patient whose urine examination shows (1) a persistently low output of high specific gravity, (2) a low $\mathrm{pH}$ figure, (3) a high output of free acid compared to the ammonia-combined acid is likely to have a stormy convalescence after operation.

6 . Various methods of pre-operative treatment are suggested in order to render the patient better able to stand the strain of operation without undue disturbance of metabolism.

Mr. J. Mill Renton congratulated Mr. White and Dr. Glen on having presented the subject of operation risk from a new aspect. He thought that most surgeons would agree with them in their condemnation of the drastic purgation and starvation of patients before operation, and he believed that this practice was fast disappearing. Referring to cases of Graves' disease he said that with the modern methods of preparation of the patient with rest and a course of Lugol's iodine for ten to fourteen days the dangers of thyroidectomy had been greatly reduced. In his experience patients prepared in this way stood the operation well. His experience with cases of operation on the gall-bladder had been similar to $\mathrm{Mr}$. White's, and he had listened with much interest to the account of the observations on the urinary changes which 
had been recorded by Mr. White and Dr. Glen in such patients. It was a question how much of the disturbance following operation in these cases was to be attributed to failure of liver function.

Mr. Norman Davidson-It has given me great pleasure to hear the instructive paper by Dr. Glen and Mr. White. There is no doubt that the views with regard to the preparation for operation of a patient have changed largely in the last twenty years. The day of purgation and starvation has passed, and the modern tendency is, of course, to keep the patient well supplied with fluid and glucose in the hope that a toxæmia due to the anæsthetic may be avoided. It is interesting to note that in a book such as Carson's Modern Operative Surgery it is stated that this strange condition referred to as postanæsthetic toxæmia, sometimes known as acidosis or delayed chloroform poisoning, is most commonly found in children, but occasionally affects adults also. The next statement is that the explanation of post-anæsthetic toxæmia is still wanting. The phenomenon is familiar, but the mode of origin remains quite obscure.

It is unnecessary for me to go over point by point the various signs of this very disturbing and often unlooked for condition. My own feeling about it is that chloroform in the presence of sepsis, vomiting, and diabetes is to be avoided, that the patient should not be admitted to a nursing home or hospital one day and submitted to operation the next. There is no doubt that with the high pressure of modern life the tendency is to hurry. The patient comes to consult the surgeon, and when it is known that an operation is to be performed they wish it done at once. Surgeons, I think, are now more or less convinced of the advisability of performing the operation of prostatectomy only after preliminary drainage of the bladder, in order to relieve the kidneys. I am of the opinion that with a great many other conditions which we surgeons are dealing with daily some preliminary form of treatment is advisable. One condition which has impressed itself on me is the question of operations on the biliary passages. I have noticed-and I think Dr. Glen and Mr. White referred to it in their paper-the very low output of urine in cases of 
this type. In cross-questioning gall-stone cases and cases of cholecystitis, one invariably finds that water as a beverage is never used. For years these patients have been starved of water. The urinary output is low and is highly concentrated. It is my own experience that one will have a much easier convalescence for one's patient if these cases can be put to bed and given water in large quantities, combined with some cholagogue such as "pill cholilithiasis" or even salicylate of soda.

With regard to the vomiting which goes on and is most distressing, in my own practice I try the effect of stopping fluids by the mouth and giving glucose and saline per rectum. I have given up the use of bicarbonate of soda except to use it for the purpose of washing out the stomach, the method being a big drink, say, of half a pint of warm water with a teaspoonful of bicarbonate of soda to induce-or rather to help - the patient to get the stomach clear. One of the best things that I have found has been the administration of a wineglassful of cold lager beer. I am not an advocate of alcohol, and I learned this particular tip from Sir Berkeley Moynihan. I have seen it act like a charm where vomiting has persisted, and I am unable to give any explanation. Where post-anæsthetic vomiting persists with drowsiness and slight icterus, the smell of acetone is well marked in the breath, and is to be found in the urine. On two occasions I gave insulin, ten units repeated, combined with glucose per rectum. Insulin seems to act if there is well-marked reaction to the ferric chloride test for acetone. I have not used it enough yet to say in which cases it will help and in which cases it will not help.

I have listened to this paper with lively interest. While most of us are working in the dark trying various ways and means purely empirical, Dr. Glen and Mr. White seem to have lightened our darkness to a certain extent. It is interesting that their observations with regard to the acidity or alkalinity of patients' urine should seem to have some bearing on the way in which they react to an anæsthetic.

Mr. Charles Bennett gave an outline of what he considered was contained within the term " operation risk," and discussed the type of risk in various diseases. General anæsthesia, when 
adopted, contributed part of the risk, but that would be adequately dealt with by the expert anæsthetists who followed in the discussion. He thought it was incumbent on us to try to gauge the risk in an operation of factors other than general anæsthesia. The effects of surgical trauma and hæmorrhage, and the capacity of the functions to tolerate changes set up by the operation, must be brought within review. He contrasted the problems present in such a condition as enlarged prostate, where time was available for various lines of pre-operation treatment which inevitably tended towards diminishing the risk of operation, with those in acute intestinal obstruction. Any pre-operation treatment, e.g., injection of hypertonic salt solution, which might be ventured upon in the latter disease was intended primarily to meet the deleterious effects of obstruction. Whether or not, as a secondary result, operation risk was thereby lessened, operation must be undertaken.

Mr. Roy Young thought that the subject was a much larger one than was realized. The openers of the discussion had recorded their observations on certain types of case, but there were many more risks than those which they or the speakers who had followed them had indicated. He suggested that the subject of operation risk would have to be studied more extensively before any practical conclusion could be made.

Professor James Hendry referred to value of blood transfusion in connection with operations on obstetrical and gynæcological cases in which there had been severe or continued hæmorrhage, and to the importance of choosing a suitable time for operating on cases of inflammatory conditions associated with the uterus and adnexa.

Dr. R. G. Lendrum said that the remarks of some of the speakers seemed to indicate misapprehension of the general principles which underlay the work of Mr. White and Dr. Glen. He believed that this work, which was of the nature of a preliminary investigation of the problems involved, might be developed to give results of importance. In his view, previously existing abnormalities of hepatic function were a 
possible basis of many of the unforeseen disturbances which followed operation, and he felt sure that the methods of study of operation risk devised by the openers of the discussion might be followed up by others.

Dr. Joshua Ferguson expressed his admiration for the way in which the problems of operation risk had been approached by Mr. White and Dr. Glen. He suggested that as they had investigated the question mainly from the biochemical side, they had laid little stress on the psychic factor, which was a potent one in determining the risk which the individual patient incurred. To the surgeon the operation was an episode in a series, but to the patient it was probably the most exciting event in his life; therefore the emotional factors of suspense, anxiety, or fear, with their direct effects on secretion, pulserate, and blood-pressure, had to be reckoned with and appropriately countered. He hoped that further reference would be made to this point at the next meeting of the Society. He agreed with Dr. Lendrum that the importance of the research of $\mathrm{Mr}$. White and Dr. Glen lay in the general principles upon which it was based and which had been supported by the investigation of a sufficiently large number of cases.

\section{REFERENCES.}

1 Ellis, Reaction in Relation to Disease, London.

2 Davis and Rixon, Brit. Med. Jour., 1927, vol. i, p. 758.

3 Barber and Oriel, Lancet, 1928, vol. i, p. 1066. 